University of Louisville

ThinkIR: The University of Louisville's Institutional Repository

Electronic Theses and Dissertations

1941

\title{
The system benzene-methyl alcohol : ?b densities, refractive indices, boiling points, and specific heats.
}

Samuel Rosenberg 1918-

University of Louisville

Follow this and additional works at: https://ir.library.louisville.edu/etd

Part of the Chemical Engineering Commons

\section{Recommended Citation}

Rosenberg, Samuel 1918-, "The system benzene-methyl alcohol : ?b densities, refractive indices, boiling points, and specific heats." (1941). Electronic Theses and Dissertations. Paper 1879.

https://doi.org/10.18297/etd/1879

This Master's Thesis is brought to you for free and open access by ThinkIR: The University of Louisville's Institutional Repository. It has been accepted for inclusion in Electronic Theses and Dissertations by an authorized administrator of ThinkIR: The University of Louisville's Institutional Repository. This title appears here courtesy of the author, who has retained all other copyrights. For more information, please contact thinkir@louisville.edu. 
DNIVERSITY OF IOUISVIILE

\author{
THE SYSTHEM BENIENE - METHYL ALCOHOL \\ PART I - DENSITIES, REFRACTIVE INDICES, \\ BOILING POINTS, AND SPECIFIC HEATS
}

\author{
A Thesis \\ Submitted to the Faculty \\ of the Graduate School \\ of the University of Louisvilie \\ in Partial Fulfillment \\ of the Requitrements \\ for the Degree of
}

MASTER OF CHEMICAL ENGINEERDNO

Department of Chomlool Inglneering

\title{
By
}

Samuel Rosenberg

1941 
THE SYSTEM BENZENE - METHYL ALCOHOL

PART I - DENSITIES, REFRACTIVE INDICES,

BOIIING POINTS, AND SPBCIFIC HEATS

Samal Rosenberg

Approved by the Examining Comittee:

Director ............

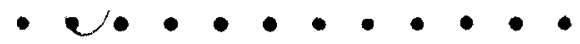

August 14, 1941 


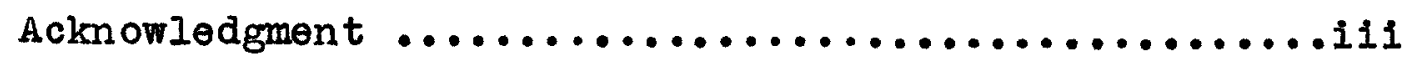

Abstract ................................1v

Iist of Figures $\ldots \ldots \ldots \ldots \ldots \ldots \ldots \ldots \ldots \ldots \ldots \ldots \ldots \ldots \ldots \ldots$

Ilst of Tables ............................

Introduction $\ldots \ldots \ldots \ldots \ldots \ldots \ldots \ldots \ldots \ldots \ldots \ldots \ldots \ldots \ldots \ldots \ldots \ldots$

Historical ................................4

Matorials ...................................

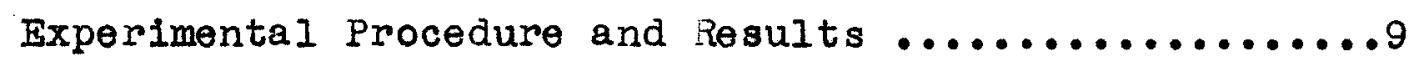

1. Determination of Density versus

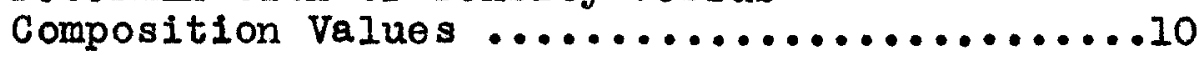

2. Determination of Refractive Index

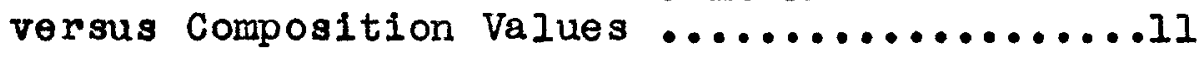

3. Determination of Bolling Point Diagram (a) ...14

4. Determination of Bolling Point Diagram (b) ...18

5. Determination of Equilibrium Diagram .......23

6. Determination of Specific Heat versus Composition .........................23

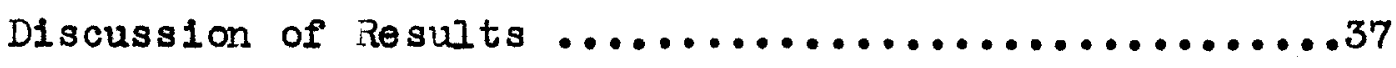

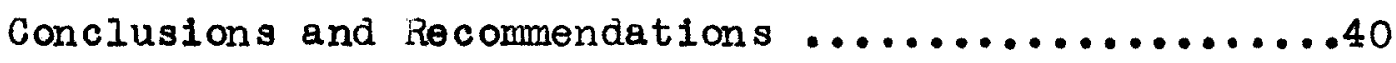
Appendix ..................................42

Acknowledgment ........................43

Iiterature cited .......................444

Vita $\ldots \ldots \ldots \ldots \ldots \ldots \ldots \ldots \ldots \ldots \ldots \ldots \ldots \ldots \ldots \ldots \ldots \ldots \ldots . . \ldots 45$ 


\section{ACKNOWLEDGMENT}

The Author wishos to acknorledge the

kind assistance and helpful guidance

of Doctor G. C. W1111ams, who

direoted this researoh. 


\section{ABSTRACT}

This thesis presents information on the binary system benzene-methyl alcohol. The system is show to be of a minimum boiling point type and does not follow the normal laws of solutions.

Experimental procedures and apparatus are described for the determination of several physical property curves for the mixture. Complete data and curves are presented for densities, refractive indices, bolling points, and vapor-11quid equilibriums. Specific heat curves are included but are considered to be of doubtful significance.

Further work is indicated on the latter data as well as the equilibrium enthalpy relationships of the system. 
IIST OF FIGURES

Page

Figure 1 Density versus Composition ..............13

Figure 2 Refractive Index versus Conposition ........15

Figure 3 Othmer Apparatus $\ldots \ldots \ldots \ldots \ldots \ldots \ldots \ldots \ldots$

Flgure 4 Batch Distillation Unit ..............20

Figure 5 Boiling Point Diagram ...............21

Figure 6 Equilibrium Diagram ................25

Figure 7 Apparatus for Determination of

Specific Heats ....................27

Figure 8 Experimental Specific Heat Data .........32

Figure 9 Specific Heats of Benzene-Methanol

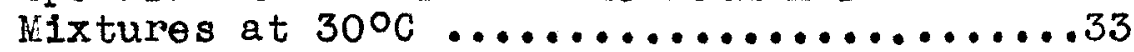

Figure 10 Specific Heats of Benzene-Methanol

Mixtures at $40^{\circ} \mathrm{C}$........................34

Figure 11 Specific Heats of Benzene-Methanol

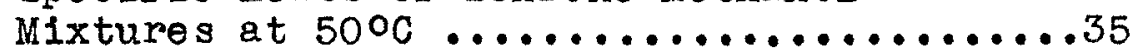

Figure 12 Derived Specific Heat Curves .............36 


\section{IIST OF TABLES}

Page

Table I Average Densities and Refractive Indices of Benzene-Methanol Mixtures

Table II Iiquid-Vapor Equilibria by the

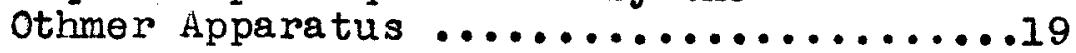

Table III Temperature-Vapor Equilibria of Boiling Benzene-Methanol Mixtures ......24

Table IV Calorimeter Calibration Data ..........29

Table V Summary Data for Speciflc Heats .31 
INTRODUCTION 
Sereral theoretical methods are now employed for the determination of the number of plates necessary in a distillation design problem. Of these, the more frequently used are the methods of Lewis (5), MoCabe and Thiele (1), Smoker (7), and Ponchon and savarit (6). Although each method has its advantages, each also has its Iimitations. Theoretically, the system of Ponchon and Savarit is the most accurate when used on systems having a simple equilibrium diagram of the type represented by the system benzene-toluene.

To date, however, the method has not been employed on a system having a constant bolling mixture such as benzene-methyl alcohol (methanol).

The data necessary for the use of the method of Ponchon and Savarit are:

1. Liquid composition versus vapor composition (equilibrium diagram)

2. Equilibrizm compositions versus temperature (boling point diagram)

3. Composition versus enthalpy of liquid and vapor equilibria.

The disadvantage of this method is that, in practicaliy all cases, the larger part of the necessary data is not available. Neither is there any publishod literature dealing with the application of this procedure to a system exhibiting a constant bolling point in its equilibrium curve. Hence, the problem of this thesis is 
to obtain the preliminary data on the system chosen, to furnish information in the published ifterature, and to allow an initial investigation of the application of this procedure.

This preliminary investigation involves determinations of densities, refractive indices, bolling points, liquidvapor equilibria, and specific heats for mixtures of benzene and methanol of all concentrations. 
HISTORICAL 
Previous to the publication of the method of dist1llation calculation as set forth by Ponchon and Savarit, the most frequently used method was that of McCabe and Thiele. This method is based on several assumptions which may be incorrect in many applications.

These assumptions, however, are normaliy taken care of In a factor which is called the plate efficiency. Bocause this method is so rapid and because only the equilibrium diagram is necessary for 1ts application, it has met with considerable acceptane by the engineering profession.

Several of these assumptions are :

(1) Constant molar overfiow

(2) Zero heat of mixing

(3) Zero radiation loss

(4) Sensible heat changes through the tower are negligible in comparison to the latent heat

(5) The algebraic sum of (2), (3), and (4) is zero. The process of distillation is one of the transfer of heat from a vapor to a liquid. Hence, it can be seen that the first assumption is incorrect unless the molal latent heats of vaporization of the components are equal. As would be expected, therefore, the Mocabe and Thiele method shows greater deviations for systems in which the latent heats of vaporization differ greatly than for systems in which these heats are more nearly equal. 
It also can be seen that a true analy81s of the problem of separation by distillation should be built around the assumption of constant enthalpy from plate to plate. The method of Ponchon and savarit assumes that the mass heat transfer from plate to plate is a constant. From this assumption the method of Ponchon and Savarit was dereloped in which the composition of liquid is plotted against the enthalpy of the liquid and composition of vapor is plotted against the enthalpy of the vapor.

This method has been proven to work falriy well for systems having a smple boliling point diagram, such as benzene-toluene, n1trogen-oxygen, and amonla-water. To date no work has been dome on the method as applied to systems having a minimum boiling mixture, such as benzenemothyl alcohol. 
MA TERIALS 
The materials used in the experimental work of this thesis were C. P. grade methyl alcohol obtalned from the Peaslee-Gaulbert Paint Company and Reagent grade benzene obtained from E. H. Sargent and Company, Chicago, Illinois.

These were purifled for use by triple distillation through a glass packed distillation tower. In each of the distillations heads and tails of about $10 \%$ were discarded and the final product of benzene and methyl alcohol distilled entirely within a range of $0.1^{\circ} \mathrm{C}$.

The specifications for these materials are:

Benzene

Experimental I.C.T.

Color

odor

Density

Boiling Point

Characteristic

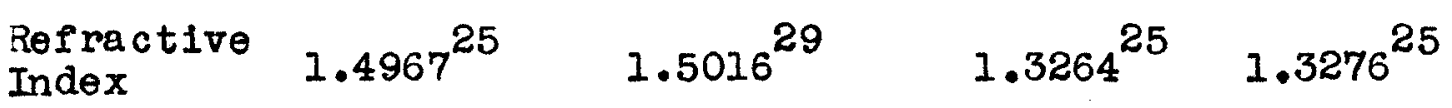

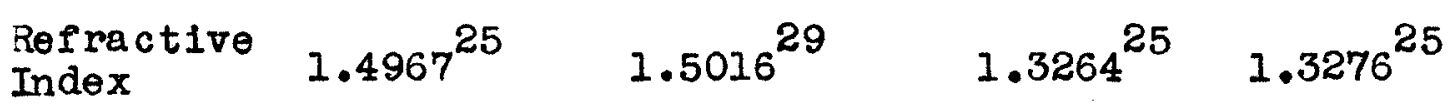

Methanol

Experimental I.C.T.

Water white

Non-pungent

$0.7865^{25}$

$0.7910 \frac{15}{4}$

$64.10 \mathrm{C}$ $64.1{ }^{\circ} \mathrm{C}$

After purification the methanol was kept in a bottle closely fitted with a rubber stopper and the benzene was stored in a bottle closely fitted with a cork stopper wrapped in tin foil. 
EXPERINEW TAI

PROCEDURE AND RESULTS 
1: Determination of Density versus Composition Values.

A standard Festphal balance was used for the determination of this data. Samples of the following compositions were made up with a Mohr pipotte graduated to 0.1 cc and placed in olean dry test tubes closely fitted with tin foll wrapped stoppers.

\begin{tabular}{|c|c|c|}
\hline $\begin{array}{l}\text { Sample } \\
\text { Mumber }\end{array}$ & $\begin{array}{c}\text { Volume Per Cont } \\
\text { Benzene }\end{array}$ & $\begin{array}{c}\text { Volume Per Cent } \\
\text { Mothanol }\end{array}$ \\
\hline 1 & 100 & 0 \\
\hline 2 & 90 & 10 \\
\hline 3 & 80 & 20 \\
\hline 4 & 70 & 30 \\
\hline 5 & 60 & 40 \\
\hline 6 & 50 & 50 \\
\hline 7 & 40 & 60 \\
\hline 8 & 30 & 70 \\
\hline 9 & 20 & 80 \\
\hline 10 & 10 & 90 \\
\hline 11 & 0 & 100 \\
\hline
\end{tabular}

The samples wero placed in a water beth kept at $25^{\circ}$ $\pm 0.5^{\circ} \mathrm{C}$. The westphal balance was then checked against distilled water at $25^{\circ} \neq 0.5^{\circ} \mathrm{C}$ and set to correspond with that in the International Critical Tables (2).

A sample was taken from the bath, and the approximate density quickly determined with the balance. The sample was replaced in the bath for at least ten minutes and the bob 
of the balance dried thoroughly. The density was again determined, this time more accurately and the sample again replaced in the beth. This procedure was repeated until the density checked to the fourth decimal place for each sample. These data were collected and are shown in table I.

The plot of these data both as density versus mol per cent composition and as density versus volume per cent composition is shown in figure 1.

2: Determination of Refractive Index versus Composition Values.

An Abbe refractometer was used for the determination of this property. The same samples used for the determination of the composition versus density plot were used for this phase of the procedure.

A water supply was prepared at a temperature to maintain the refractometer at $25^{\circ} \mathrm{C}$. Then the water from this supply was mun through the refractometer and the temperature of the instrument kept at $25^{\circ} \pm 0.5^{\circ} \mathrm{C}$ by regulating the rate of flow.

Each sample was placed in the water supply for at least ten minutes before 1 ts refrective index was mu. At this time the sample was removed from the bath and a dropper immersed in the tube. This first dropperful of sample was discarded and a second quickly taken.

This material was then inserted between the ground glass plates of the refractometer and the refractive index 


\section{TABLE I}

Average Densities and Refractive Indices of Benzene-Methanol Mixtures

\begin{tabular}{|c|c|c|c|c|c|c|}
\hline $\begin{array}{c}\text { Sample } \\
\text { No. }\end{array}$ & $\begin{array}{l}\text { Volume \% } \\
\text { Benzene }\end{array}$ & $\begin{array}{l}\text { Volume \% } \\
\text { Me thanol }\end{array}$ & $\begin{array}{c}\text { Mol \% } \\
\text { Benzene } \\
\end{array}$ & $\begin{array}{c}\text { Mol \% } \\
\text { Methanol } \\
\end{array}$ & $\begin{array}{l}\text { Density } \\
\text { at } 25^{\circ} \mathrm{C} \\
\end{array}$ & $\begin{array}{c}\text { Average } \\
\text { np at } 25^{\circ} \mathrm{C} \\
\end{array}$ \\
\hline 1 & 0 & 100 & 0 & 100 & 0.7865 & 1.3264 \\
\hline 2 & 10 & 90 & 4.81 & 95.19 & 0.7960 & 1.3429 \\
\hline 3 & 20 & 80 & 10.21 & 89.79 & 0.8040 & 1.3595 \\
\hline 4 & 30 & 70 & 16.29 & 83.71 & 0.8128 & 1.3765 \\
\hline 5 & 40 & 60 & 23.28 & 76.72 & 0.8230 & 1.3942 \\
\hline 6 & 50 & 50 & 31.25 & 68.75 & 0.8320 & 1.4121 \\
\hline 7 & 60 & 40 & 40.60 & 59.40 & 0.8410 & 1.4296 \\
\hline 8 & 70 & 30 & 51.50 & 48.50 & 0.8495 & 1.4471 \\
\hline 9 & 80 & 20 & 64.50 & 35.50 & 0.8576 & 1.4640 \\
\hline 10 & 90 & 10 & 80.10 & 19.90 & 0.8653 & 1.4809 \\
\hline 11 & 100 & 0 & 100 & 0 & 0.8724 & 1.4967 \\
\hline
\end{tabular}




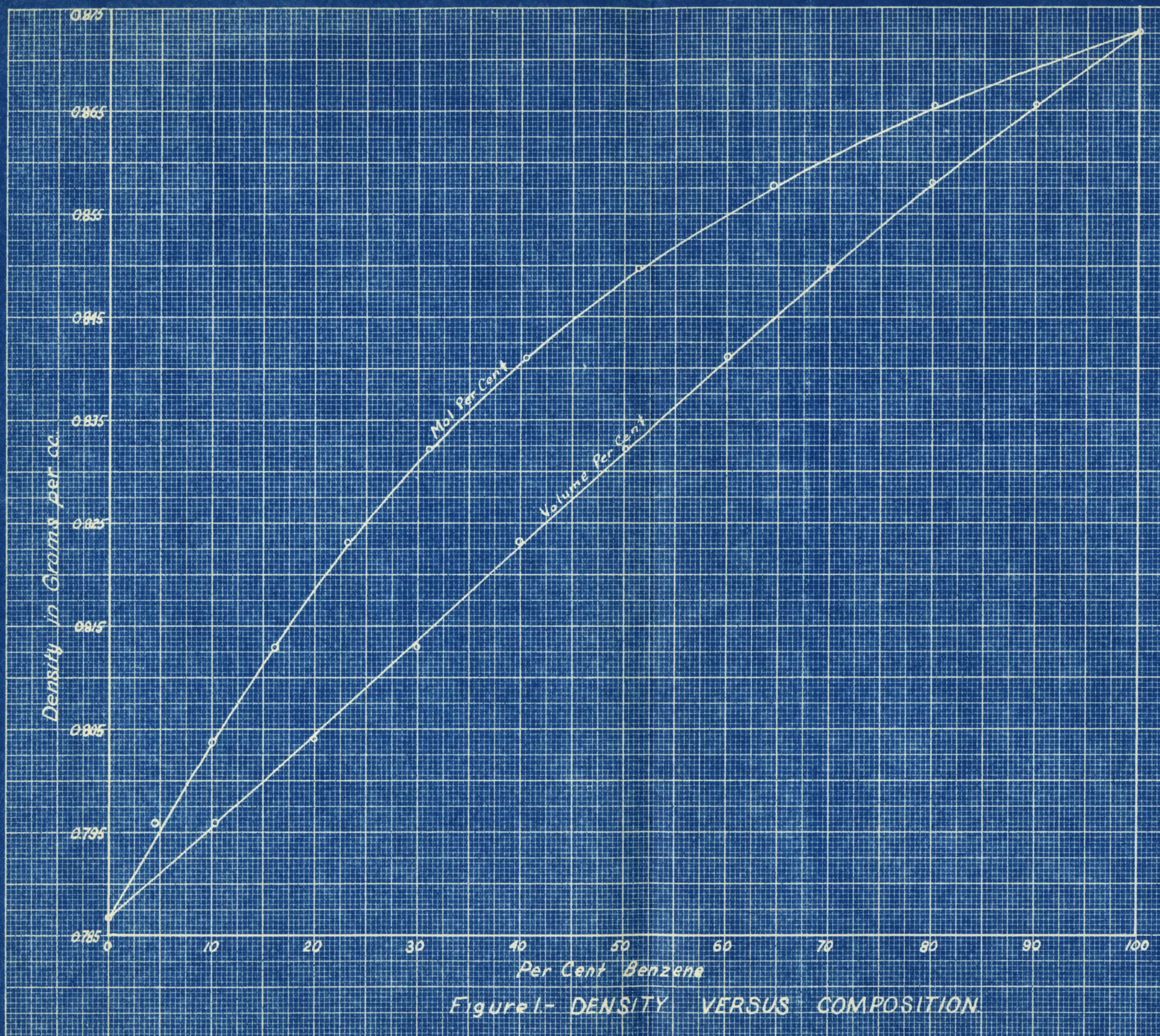


determined to four decimal places. The original sample was replaced in the bath for an additional ten minutes to bring it to $25^{\circ} \pm 0.500$.

The refractometer was dried with Iens tissue and the process repeated on the same sample. This was continued until three readings were obtalned which were within 0.0003 of each other. These were recorded and the arithmetical average taken as the refractive index of the sample at $25^{\circ} \mathrm{C}$. The process was repeated with all samples and their refractive indices determined in the same manner.

These data were collected and are shown in table I. Graphically they are plotted both as refractive index versus mol per cent composition and refractive index versus volume per cent composition in figure 2 .

3: Determination of Bolling Point Diagram (a).

A. Theory of Othmer Bolling Point Apparatus

In order to prepare the boiling point diagram and hence the equilibrium diagram, it is necessary to employ a unit of the othmer type or 1ts equivalent.

The un1t, see figure 3 , is a closed circuit with a condenser at one point. Vapor from the boiling liquid in the system is condensed and returned to the main charge. This process continues until the composition of the vapor leavIng the main body of the liquid is the same as that of the Ilquid overflowing from the well below the condenser. At 


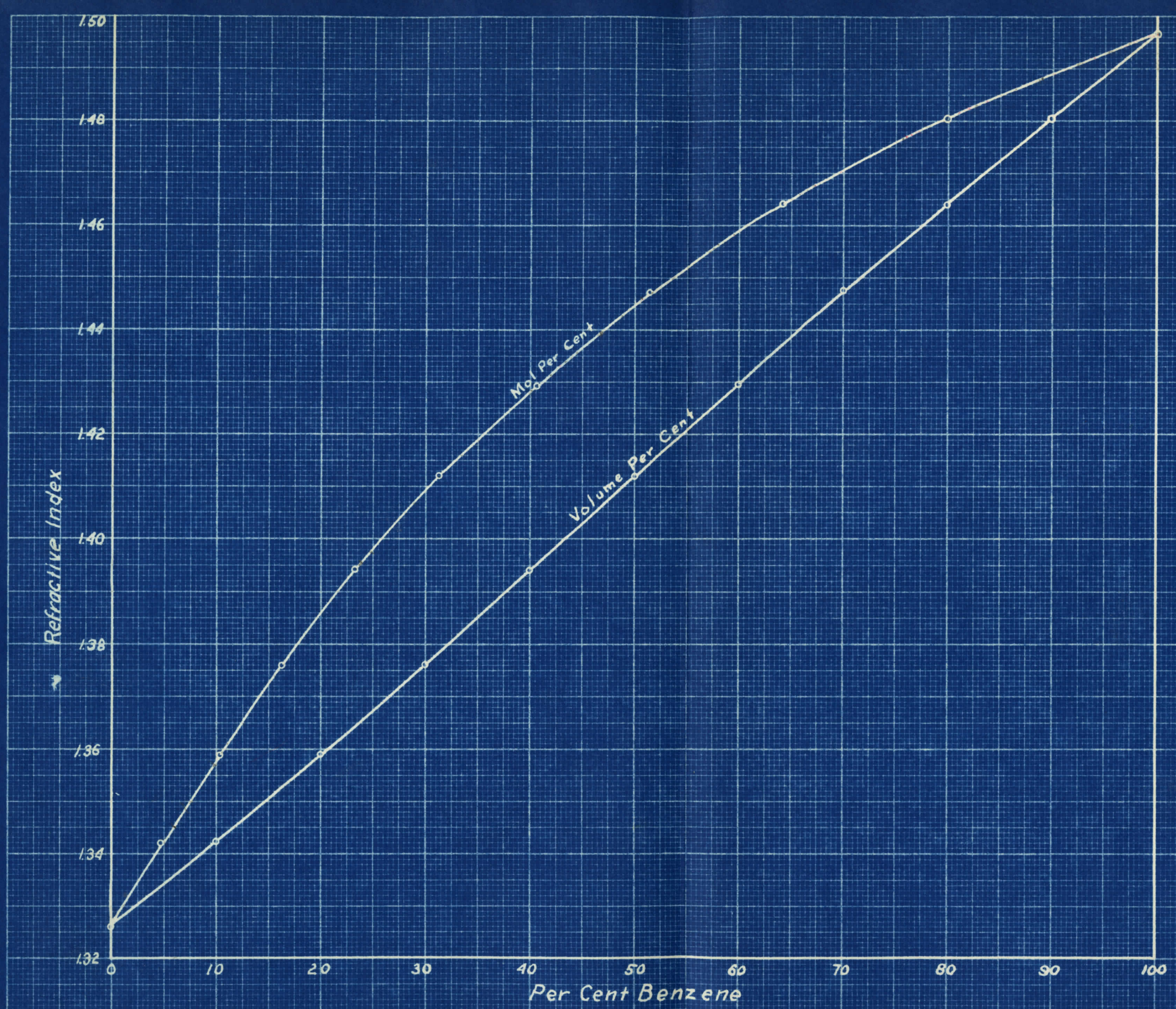

FIgUTE 2. REFRACTIVE INDEX VERSUS COMPOSITION 


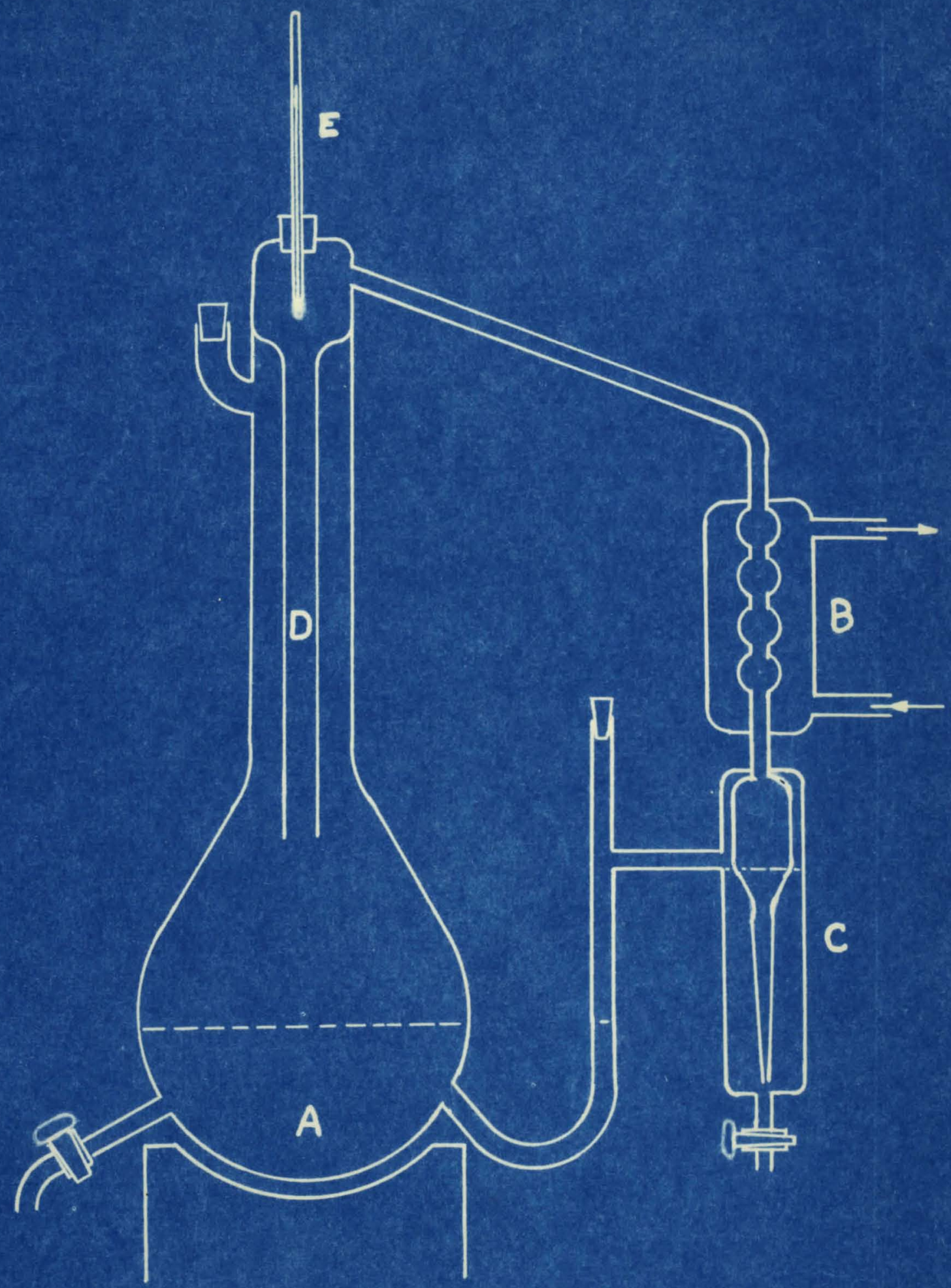

Figure 3.- Othmer A pparatus. 
this point the temperature of the system is a constant, and the system is in equilibrium. Samples of the boiling Iiquid and of the condensed vapor are obtained and their composition determined by means of the refractive indices of the samples.

\section{B. Procedure}

The apparatus was set up as shown in figure 3. A mixture of purified benzene and purifled methyl alcohol was placed in the bottom of the container at A. Heat was applled here, and the vapor was condensed in the condenser $B$ and collected in the reservolr $C$. The lead to this well was mun almost to the bottom so that the addition of more condensate caused the Ilquid at the top to overflow and a continuous change of material in the well was the result.

The tube $D$ to the condenser was completely enclosed by a vapor jacket to eliminate droplets in the vapor. In this manner, the vapor reaching the condenser was assured of being in equilibrium with the liquid in A. The temperature of this vapor was determined by means of the $0.1^{\circ} \mathrm{C}$ thermometer placed at $\mathbf{E}$.

As the condensate overflowed from $C$, it was returned to A so that in time, the composition of vapor leaving the Iiquid was the same as the composition of the IIquid overflowing from the reservolr. This was shown by the constant reading on the the rmometer. By taking samples from $C$ and $A$, the vapor in equilibrium with the liquid was obtained. The composition of these two mixtures were 
then determined by means of their refractive indices at $25^{\circ} \mathrm{C}$. These values when compared with the plot of refractive Index versus composition resulted in the composition of the samples. These compositions were plotted against the temperature at which the system was in equilibrium to obtain two points on the boiling point diagram.

By adding a slight amount of one material the run was repeated and another two points obtained on the curve. This was repeated until sufficient points had been obtained to define the curve definitely. The data taken from this procedure are shown in table II.

The plot of vapor composition versus temperature and of I1quid composition versus temperature is shown on figure 5 .

4: Determination of Boiling Point Diagram (b).

A. Theory

Before the vapor portion of the boling point diagram was determined for mixtures containing less methyl alcohol than that in the constant boiling mixture, the othmer apparatus was damaged beyond use. Hence another method for this determination had to be devised.

The method proposed to obtain the data for this curve was one employing the following system:

A mixture of purified benzene and purified methyl alcohol was placed in a small flask and slowly heated. Sam- 


\section{TABLE II}

Ilquid-Vapor Equilibria by the Othmer Apparatus.

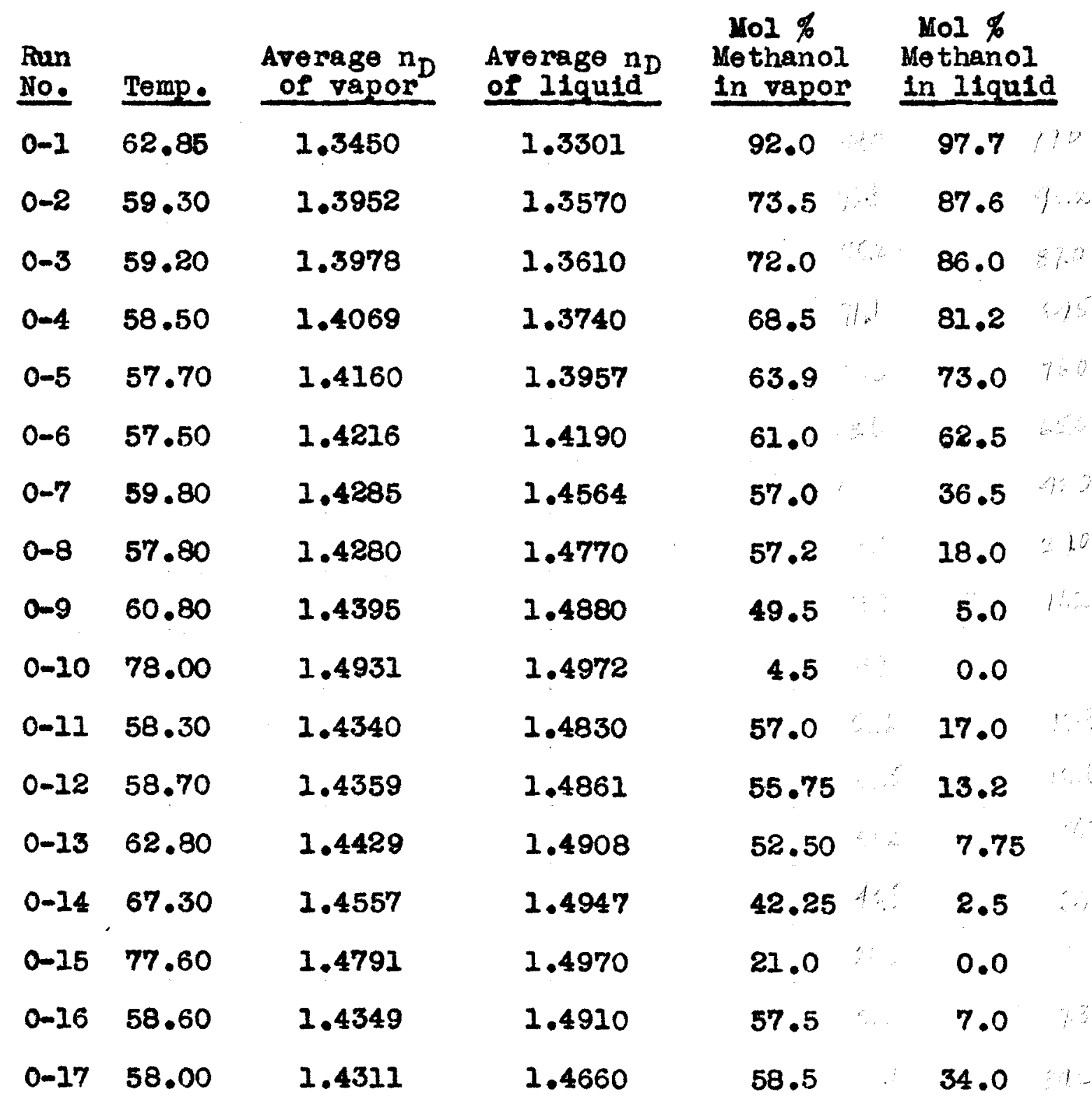




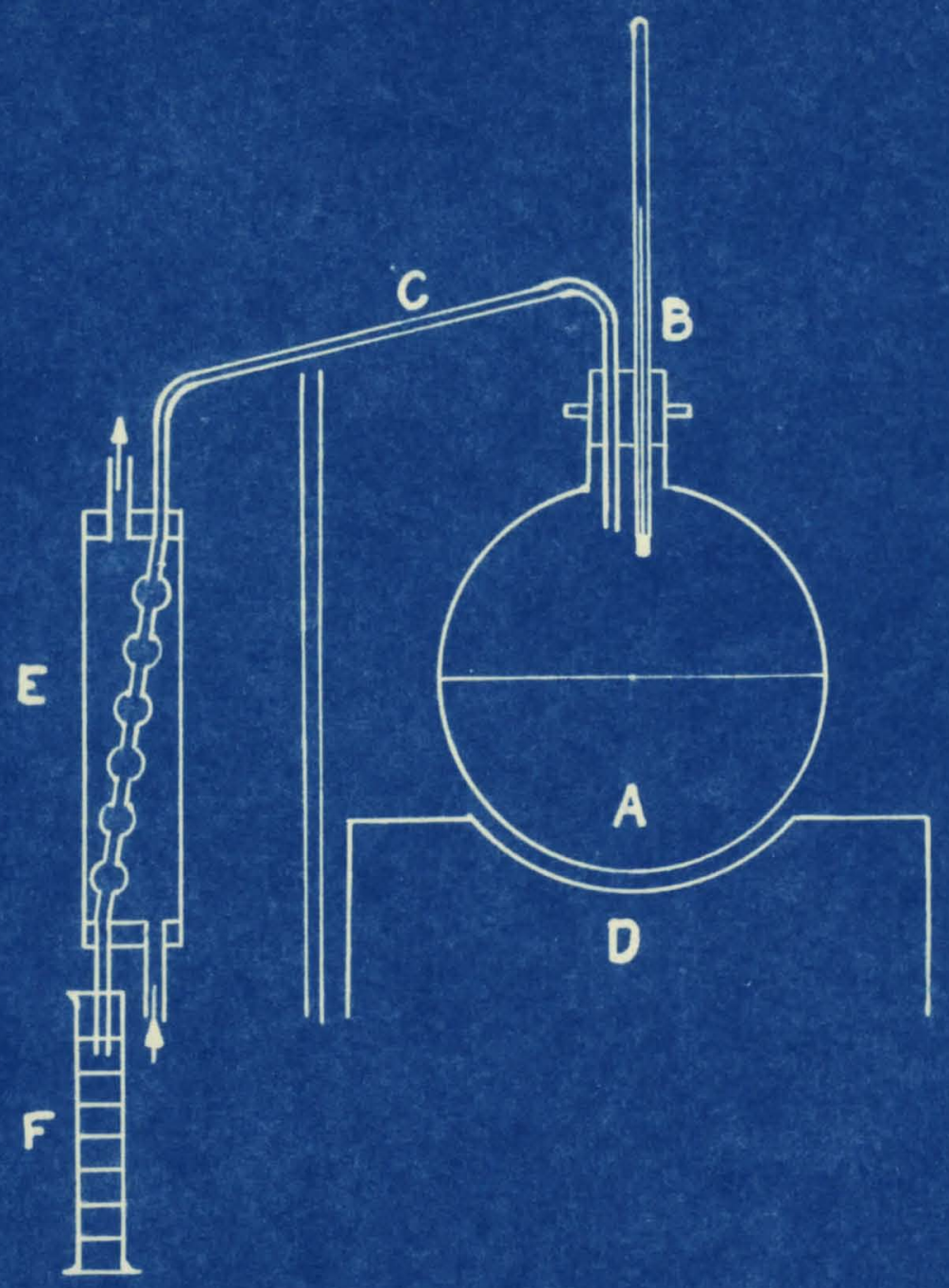

Figure 4.- Batch Distillation Unit. 


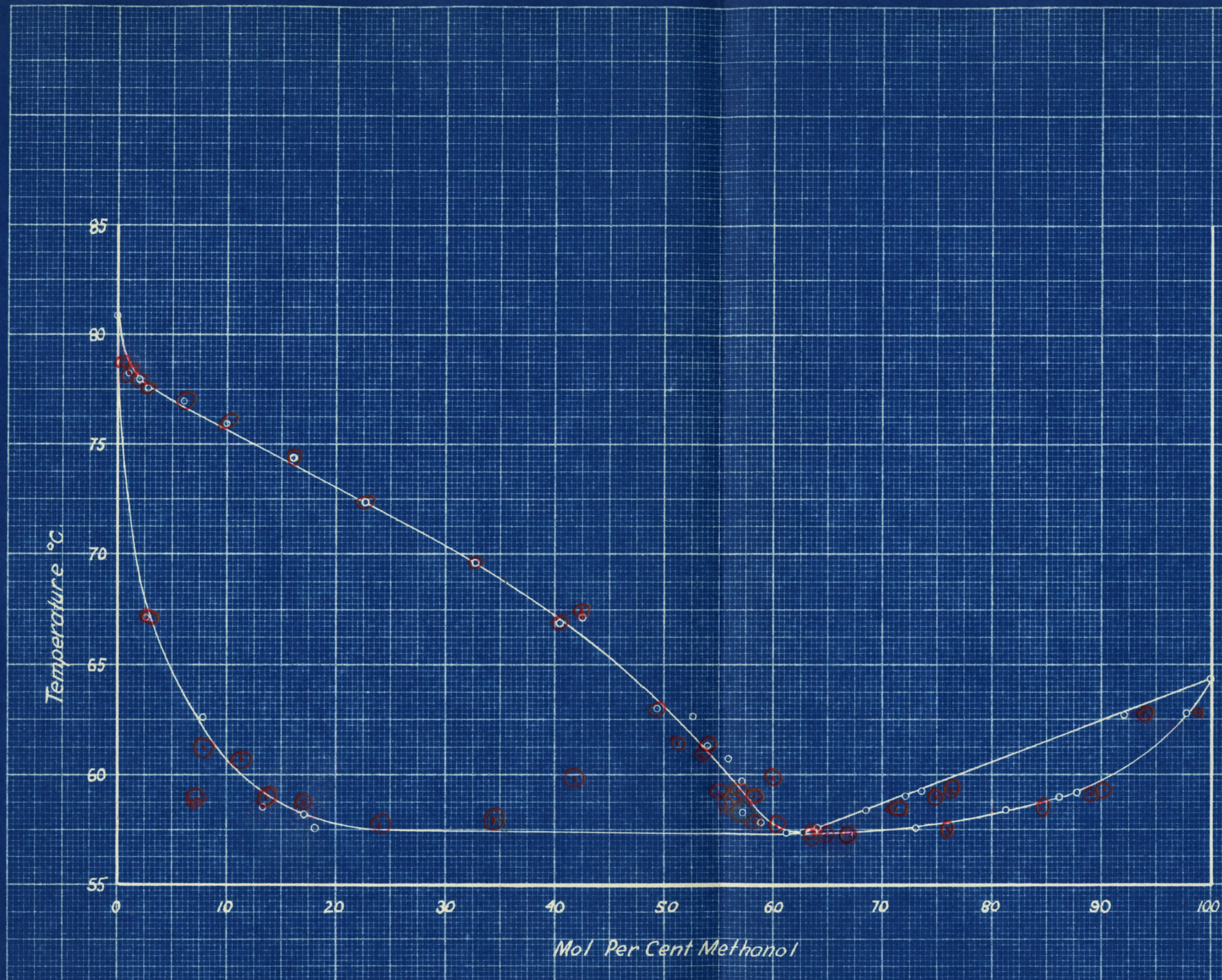

Figure 5- BOILING POINT DIAGRAM. 
ples were taken through a short lead tube run through a condenser. The temperature at the start of the sample and at the end of the sample were recorded.

Since the heating was slow, the lead tube short and insulated, and the samples taken were small, the average temperature could be plotted against the average composition of the sample as shown by means of the refractive indices of the samples. This resulted in reproducible data which gave the vapor curve of the equilibrium diagram to the left of the constant boliling mixture.

B. Apparatus

The apparatus used for this determination was set up as shown on figure 4. It consisted of a 500 cc round bottom Plask at A. A $0.2^{\circ} \mathrm{C}$ thermometer was placed at B. The lead tube $C$ was as short as possible. It was also slanted downward to insure no retum of any condensate to the flask. Heat was applied at $D$. The condenser was water cooled and led directly to the graduated receiver $F$.

\section{Procedure}

A mixture of purified methyl alcohol and purified benzene was prepared which contained slightly less methyl alcohol than the constant bolling mixture. This mixture was placed in the flask A. This was slowly heated and the vapors condensed at $\mathrm{E}$. 
As the distillation progressed, the distillate was collected in the graduate at $F$, and when four $c c$ had been accumulated, the graduate was replaced with one that was clean and dry. This sample was then transferred to a clean, dry test tube and labeled. The temperatures at the start and finish of the four cc were also recorded as read at $B$.

When the temperature in the flask had risen to within about $0.5^{\circ} \mathrm{C}$ of the boiling point of pure benzene, the min was stopped.

The compositions of the samples were then determined by means of their refractive indices at $250 \mathrm{C}$. The data for this set of runs are shown in table III. This composition was then plotted against the average temperature at which the sample distilled over.

This procedure resulted in the vapor curve of the bolling point diagram.

5. Determination of Equilibrium Diagram.

A. Procedure

In order to prepare this plot of liquid composition versus vapor composition at equilibrium, it was necessary only to plot the compositions of liquid and vapor as shown in the boiling point diagram. This plot is shown in figure 6 .

6. Determination of Plot of Specific Heat versus Composition. A. Theory 


\section{TABLE III}

Temperature-Vapor Equilibria of Bolling

Benzene-Methanol Mixtures

\begin{tabular}{ccccc} 
Run No. & $\begin{array}{c}\text { Average } \\
\text { Temperature }\end{array}$ & Average $n_{D}$ & $\begin{array}{c}\text { Mol \% } \\
\text { Methanol }\end{array}$ \\
\cline { 5 - 5 } BP-1 & 58.0 & & 1.4313 & 58.5 \\
BP-2 & 61.4 & 1.4390 & 53.8 \\
BP-3 & 63.1 & 1.4460 & 49.3 \\
BP-4 & 67.1 & 1.4582 & 40.4 \\
BP-5 & 69.7 & 1.4677 & 32.5 \\
BP-6 & 72.4 & 1.4777 & 22.6 \\
BP-7 & 74.4 & 1.4838 & 16.0 \\
BP-8 & 76.1 & 1.4890 & 9.8 \\
BP-9 & 77.1 & 1.4921 & 6.0 \\
BP-10 & 77.6 & 1.4946 & 2.7 \\
BP-11 & 78.0 & 1.4951 & 2.0 \\
BP-12 & 78.3 & 1.4960 & 0.9 \\
BP-13 & 78.5 & 1.4961 & 0.8 \\
BP-14 & 78.6 & 1.4966 & 0.1
\end{tabular}




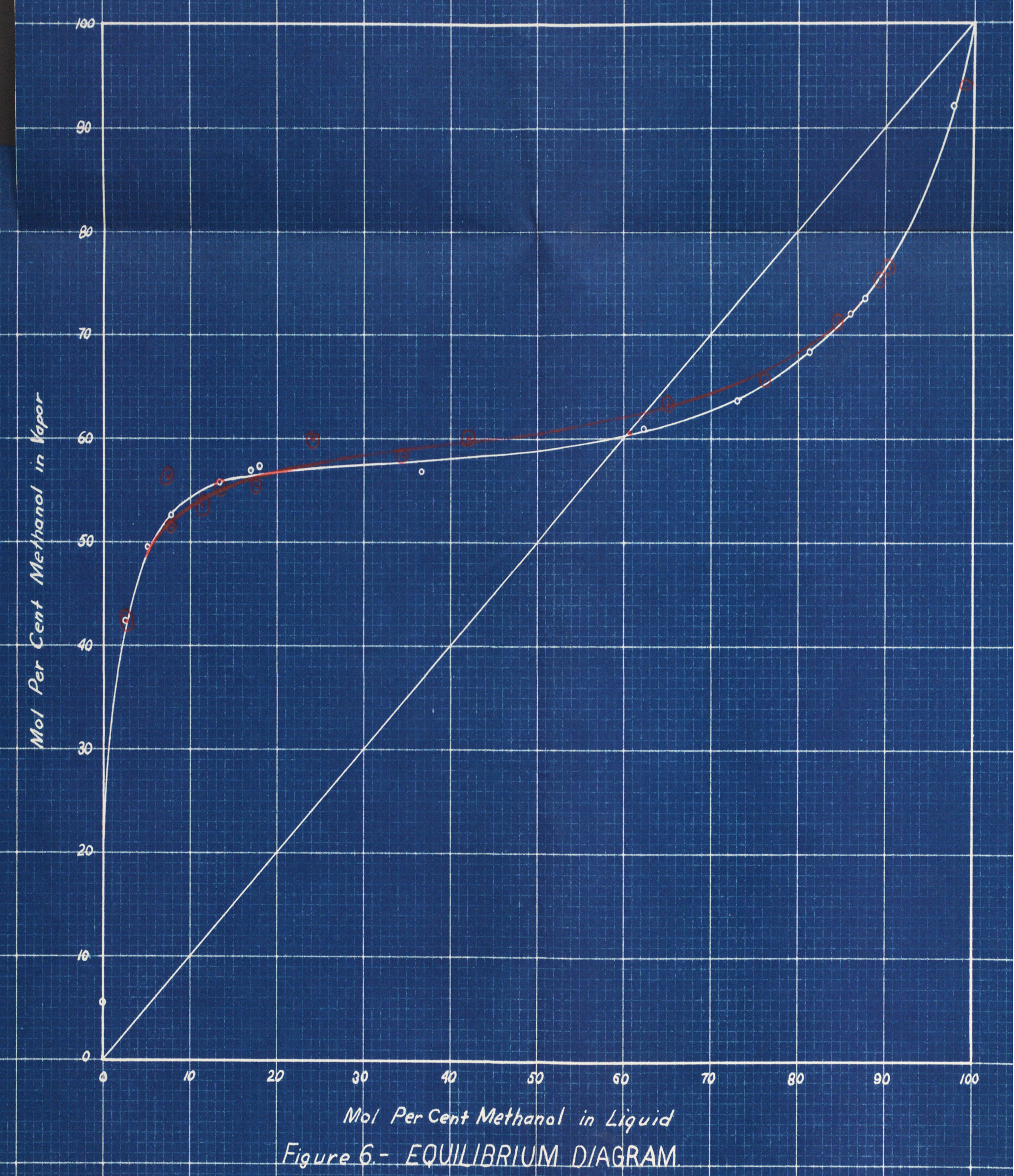


The specific heat of a liquid is defined as the heat necessary to raise a unit mass of the material one degree in temperature on some temperature scale.

Thus, by adding a known amount of heat to a known amount of liquid and recording the temperature rise, the specific heat could be calculated. Heat was added by means of an electric coll with a voltmeter and ammeter inserted in the circult. A rheostat was also used to control the voltage drop across the coll and the current through the coil.

The heat was added for a known length of time as shown by a stop clock. Losses in the system were calculated by means of a standard liquid of known specific heat in the calorimeter, as explained subsequently.

B. Procedure

In order to determine the enthalpy of the Ifquid a standard set-up was employed (3). In this set-up, a weighed amount of pure material whose specific heat was accurately known, was placed in a calorimeter equipped with a $0.20 \mathrm{C}$ thermometer, motor driven stirrer, and heating coll.

The coil was connected across the terminals of a d-c source of supply and a voltmeter and ammeter inserted in the circuit along with a carbon plate rheostat as shown in figure 7 .

The current was allowed to man for five minutes during which time the initial temperature was recorded, the voltage 


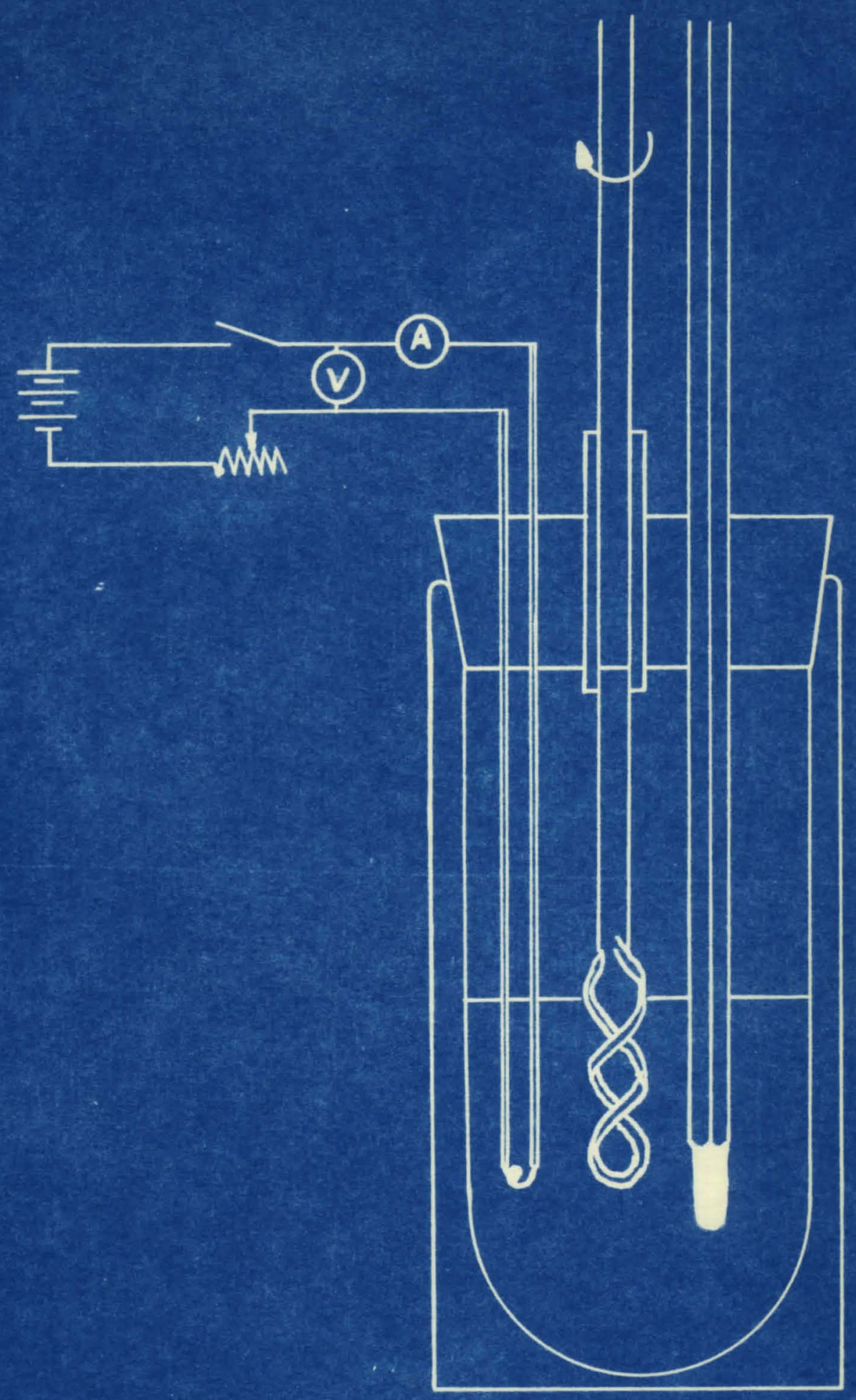

Figure 7.-Apparatus for Determination of Specific Heats. 
and current kept constant and recorded, and the maximum temperature recorded.

At the end of five minutes, the current was cut off and the stirrer allowed to run for an additional five minutes in order to determine the 10ss. The drop in temperature during the second five minutes was added to the rise during the first five minutes, and the total used in calculating the heat capacity of the calorimeter at the average temperature of the run.

The equation is,

$$
\frac{(E)(I)(t)}{(4.182)(\Delta T)}=\left(C_{p}^{\prime} W\right)+(m)\left(C_{p}\right)
$$

where $E=$ potential drop in volts,

$I=$ current in amperes,

$\Delta T=r i s e$ in first five minutes drop in second five minutes,

$t=t$ ime of heating in seconds,

$m=$ weight of liquid in grams,

$\mathrm{C}_{\mathrm{p}}=$ specific heat of liquid in gram calories per ${ }^{\circ} \mathrm{C}$.

In this equation everything is know except ( $C_{p}^{p} W$ )

which can be calculated. See table IV. When the calibration was mun on methyl alcohol, benzene, and toluene as a check, the specific heat of a mixture of benzene and methyl alcohol could be determined.

Then with the known value of $\left(C_{p}^{\prime} W\right)$ the specific heat of the mixture could be calculated at varlous temperatures. The same procedure was used and the same data were taken. These 


\section{TABLE TV}

Calorimeter Calibration with Toluene, Benzene, and Methanol Rin No. CC-1 CC-2 CC-3 CC-4 CC-5 CC-6 CC-7 CC-8 Materlal Tol. Tol. Be. Be. Be. Alc. Alc. Alc.

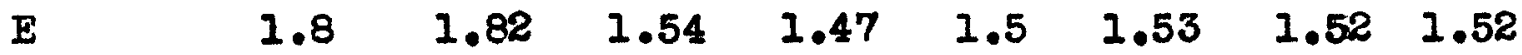
$\begin{array}{lllllllll}I & 3.0 & 2.8 & 2.8 & 2.8 & 2.8 & 2.8 & 2.8 & 2.8\end{array}$

$\mathrm{T}_{1}$

29

$41 \quad 26 \quad 50$

$60 \quad 25$

38 46

$\mathrm{T}_{2}$ $32.5 \quad 43.95$ 29.0

52.3

62

27.5

$39.85 \quad 47.7$

Tav. $30.75 \quad 42.50 \quad 27.5$

51.65

61

26.26

$38.9 \quad 46.85$

drop

0.25

0.45

0.15

0.7

1.0

0.1

0.55

0.7

$\Delta \mathrm{T}$

3.75

3.4

$3.2 \quad 3.0$

3.0

2.6

2.4

2.4

$t$

300

300

300

300

300

300

300

300

m 203.5

203.5

175.4

275.4

175.4156 .3

156.3156 .3

$c_{p}$

$0.40^{7}$

0.412

0.414

0.437

0.4440 .601

0.618

0.627

$c_{p}^{\prime} W$

20.421 .1

23.4

21.3

22.6

20

$30.4 * 30.5 *$

* These values were obtained neglecting the loss of heat by vaporization of 0.4 grams of mothanol per hour or a $10 \mathrm{ss}$ of 0.033 grams per mun of ten minutes. When corrected for this factor, the true values of $C_{p}^{\prime} W$ for these runs are 21.50 and 21.60 respectively.

The average value of $C_{p}^{\prime} W=21.50$. 
data are shown in table V. The specific heats of constant mixture compositions were plotted vergus the average temperature of the run and are shown in figure 8.

Interpolated values of $C_{p}$ were then picked off the curves for $30^{\circ}, 40^{\circ}$, and $50^{\circ} \mathrm{C}$. These values were plotted as constant temperature specific heats against varying compositions in figures 9, 10, and 11. Average curves were drawn and these assembled curves are presented in figure 12. 


\begin{tabular}{|c|c|c|c|c|c|c|c|c|c|c|c|c|c|c|c|c|c|}
\hline $\begin{array}{l}\text { Ran } \\
\text { No. }\end{array}$ & $\mathrm{T}_{1}$ & $\underline{T_{2}}$ & $T_{\text {av. }}$ & drop & $\Delta T$ & $\underline{m_{1}}$ & $\underline{m_{2}}$ & mav. & $\underline{\underline{E}}$ & $\underline{I}$ & $\underline{t}$ & QIT & $C_{p} W$ & QL & $\underline{n_{D}}$ & $\begin{array}{c}\text { Yol \% } \\
\text { Be. }\end{array}$ & $\underline{c_{p}}$ \\
\hline$E-1$ & 28.4 & 31.4 & 29.9 & 0.2 & 3.2 & 190.9 & 190.9 & 190.9 & 2.19 & 2.6 & 300 & 127.5 & 21.5 & 106.0 & 1.3854 & 19.75 & 0.555 \\
\hline $\mathrm{B}-2$ & 41.7 & 43.75 & 42.7 & 0.5 & 2.55 & 190.3 & 189.9 & 190.1 & 1.84 & 2.6 & 300 & 134.5 & 21.5 & 113.0 & 1.3854 & 19.75 & 0.594 \\
\hline $3-3$ & 52.2 & 53.7 & 52.9 & 0.9 & 2.4 & 187.4 & 187.2 & 187.3 & 1.79 & 2.6 & 300 & 139.5 & 21.5 & 118.0 & 1.3854 & 19.75 & 0.630 \\
\hline $3-4$ & 29.6 & 32.3 & 30.95 & 0.25 & 2.95 & 195.5 & 195.4 & 195.4 & 2.01 & 2.6 & 300 & 127.2 & 21.5 & 205.6 & 1.4433 & 49.0 & 0.540 \\
\hline $3-5$ & 42.3 & 43.95 & 43.1 & 0.5 & 2.15 & 194.0 & 193.8 & 193.9 & 1.52 & 2.6 & 300 & 131.9 & 21.5 & 110.4 & 1.4433 & 49.0 & 0.570 \\
\hline$E-6$ & 50.8 & 52.05 & 51.4 & 0.8 & 2.05 & 193.8 & 193.8 & 193.8 & 1.52 & 2.6 & 300 & 138.5 & 21.5 & 127.0 & 1.4433 & 49.0 & 0.605 \\
\hline $3-7$ & 29.5 & 31.9 & 30.7 & 0.2 & 2.6 & 191.0 & 190.7 & 190.9 & 1.54 & 2.6 & 300 & 120.0 & 21.5 & 88.5 & 1.4896 & 91.0 & 0.464 \\
\hline $\mathrm{E}-8$ & 42.0 & 44.0 & 43.0 & 0.5 & 2.5 & 190.8 & 190.8 & 190.8 & 1.57 & 2.6 & 300 & 117.2 & 21.5 & 95.7 & 1.4896 & 91.0 & 0.503 \\
\hline$E-9$ & 50.6 & 52.35 & 51.4 & 0.85 & 2.6 & 190.8 & 190.8 & 190.8 & 1.76 & 2.6 & 300 & 126.4 & 21.5 & 104.9 & 1.4896 & 91.0 & 0.549 \\
\hline$E-10$ & 27.0 & 29.6 & 28.3 & 0.05 & 2.65 & 150.2 & 150.5 & 150.3 & 1.54 & 2.6 & 300 & 111.0 & 21.5 & 89.5 & 1.4489 & 53.2 & 0.595 \\
\hline$E-11$ & 38.0 & 40.25 & 39.13 & 0.45 & 2.65 & 150.8 & 150.7 & 150.8 & 1.57 & 2.6 & 300 & 110.5 & 21.5 & 89.0 & 1.4489 & 53.2 & 0.593 \\
\hline $\mathrm{E}-12$ & 50.4 & 52.1 & 51.2 & 1.0 & 2.7 & 149.4 & 149.1 & 149.2 & 1.64 & 2.6 & 300 & 113.5 & 21.5 & 92.0 & 1.4489 & 53.2 & 0.616 \\
\hline $\mathrm{B}-23$ & 27.2 & 29.5 & 28.3 & 0.3 & 2.6 & 179.9 & 180.9 & 180.4 & 1.5 & 2.6 & 300 & 107.5 & 21.5 & 86.0 & 1.4585 & 59.9 & 0.477 \\
\hline$E-14$ & 38.0 & 40.6 & 39.3 & 0.6 & 3.2 & 179.6 & 179.2 & 279.4 & 1.0 & 2.6 & 305 & 112.4 & 21.5 & 90.9 & 1.4585 & 59.9 & 0.506 \\
\hline $\mathrm{B}-15$ & 54.0 & 55.2 & 54.6 & 1.2 & 2.4 & 177.7 & 177.0 & 177.4 & 1.65 & 2.6 & 300 & 127.5 & 21.5 & 106.0 & 1.4585 & 59.9 & 0.598 \\
\hline$E-16$ & 29.0 & 31.9 & 30.5 & 0.2 & 3.1 & 176.7 & 176.0 & 176.4 & 1.77 & 2.6 & 300 & 106.3 & 21.5 & 84.8 & 1.4670 & 67.0 & 0.471 \\
\hline$E-17$ & 45.8 & 48.0 & 46.9 & 0.7 & 2.9 & 275.1 & 175.0 & 175.1 & 1.72 & 2.6 & 300 & 110.4 & 21.5 & 88.9 & 1.4670 & 67.0 & 0.506 \\
\hline$E-18$ & 51.4 & 53.2 & 52.3 & 0.95 & 3.75 & 175.2 & 174.5 & 174.9 & 1.68 & 2.6 & 300 & 109.9 & 21.5 & 88.4 & 1.4670 & 67.0 & 0.506 \\
\hline E-19 & 28.2 & 30.6 & 29.4 & 0.25 & 2.65 & 163.4 & 162.9 & 163.2 & 1.45 & 2.6 & 300 & 102.5 & 21.5 & 81.0 & 1.4726 & 72.0 & 0.496 \\
\hline$x-20$ & 37.4 & 39.7 & 38.5 & 0.45 & 2.75 & 162.7 & 162.6 & 162.7 & 1.53 & 2.6 & 300 & 103.5 & 21.5 & 82.0 & 1.4726 & 72.0 & 0.504 \\
\hline$E-2 I$ & 52.6 & 54.15 & 53.37 & 1.1 & 2.65 & 160.8 & 159.7 & 160.3 & 1.63 & 2.6 & 300 & 114.4 & 21.5 & 92.9 & 1.4726 & 72.0 & 0.579 \\
\hline E-22 & 30.0 & 32.8 & 31.4 & 0.2 & 3.0 & 206.7 & 206.7 & 206.7 & 2.01 & 2.6 & 300 & 124.9 & 21.5 & 103.4 & 1.4826 & 82.7 & 0.500 \\
\hline E-23 & 48.0 & 50.0 & 49.0 & 0.7 & 2.7 & 206.4 & 205.2 & 205.8 & 1.79 & 2.6 & 300 & 123.8 & 21.5 & 102.3 & 1.4826 & 82.7 & 0.498 \\
\hline $\mathrm{E}-24$ & 54.6 & 56.35 & 55.4 & 1.0 & 2.75 & 204.5 & 204.1 & 204.3 & 1.91 & 2.6 & 300 & 129.5 & 21.5 & 108.0 & 1.4826 & 82.7 & 0.527 \\
\hline
\end{tabular}




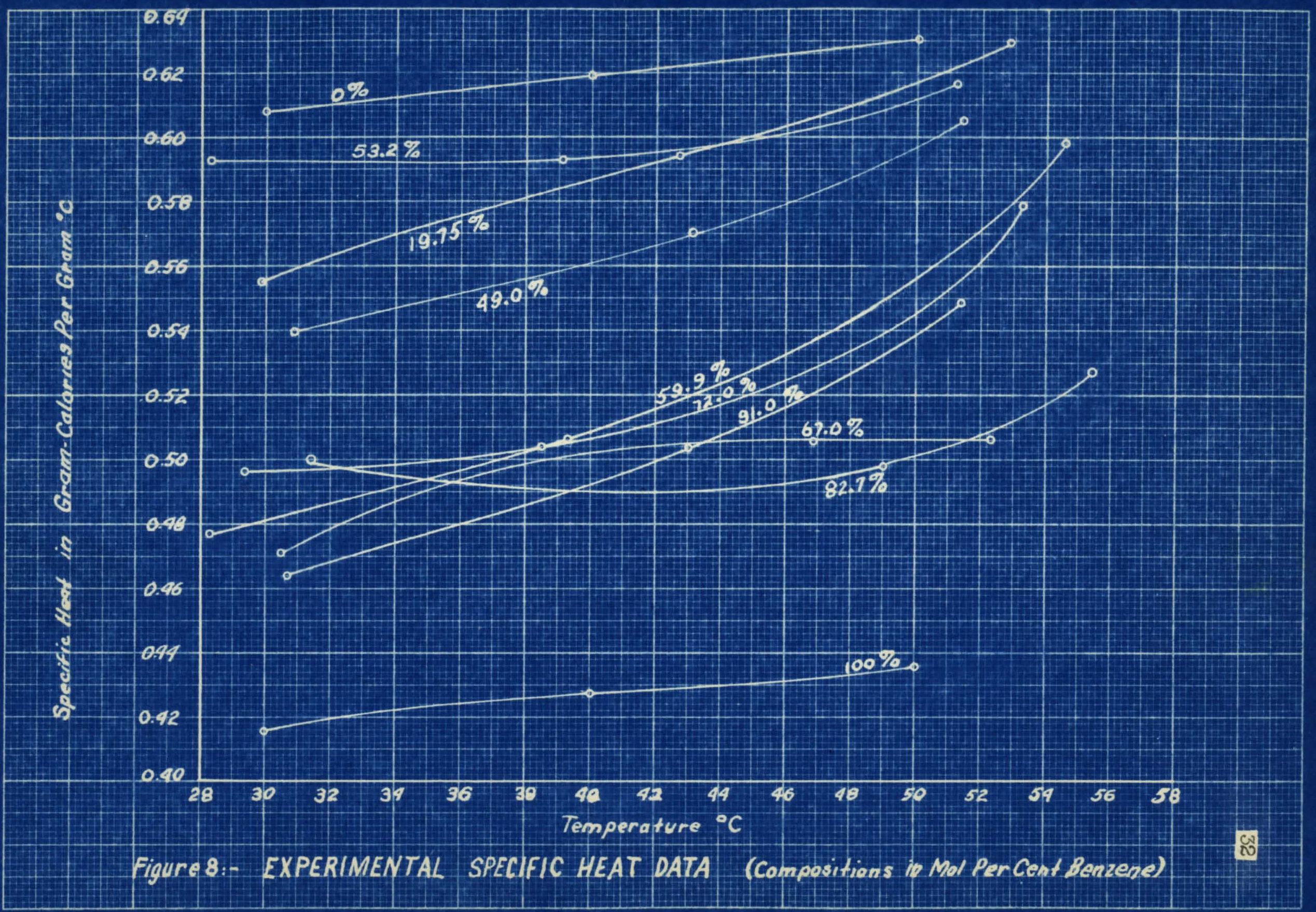




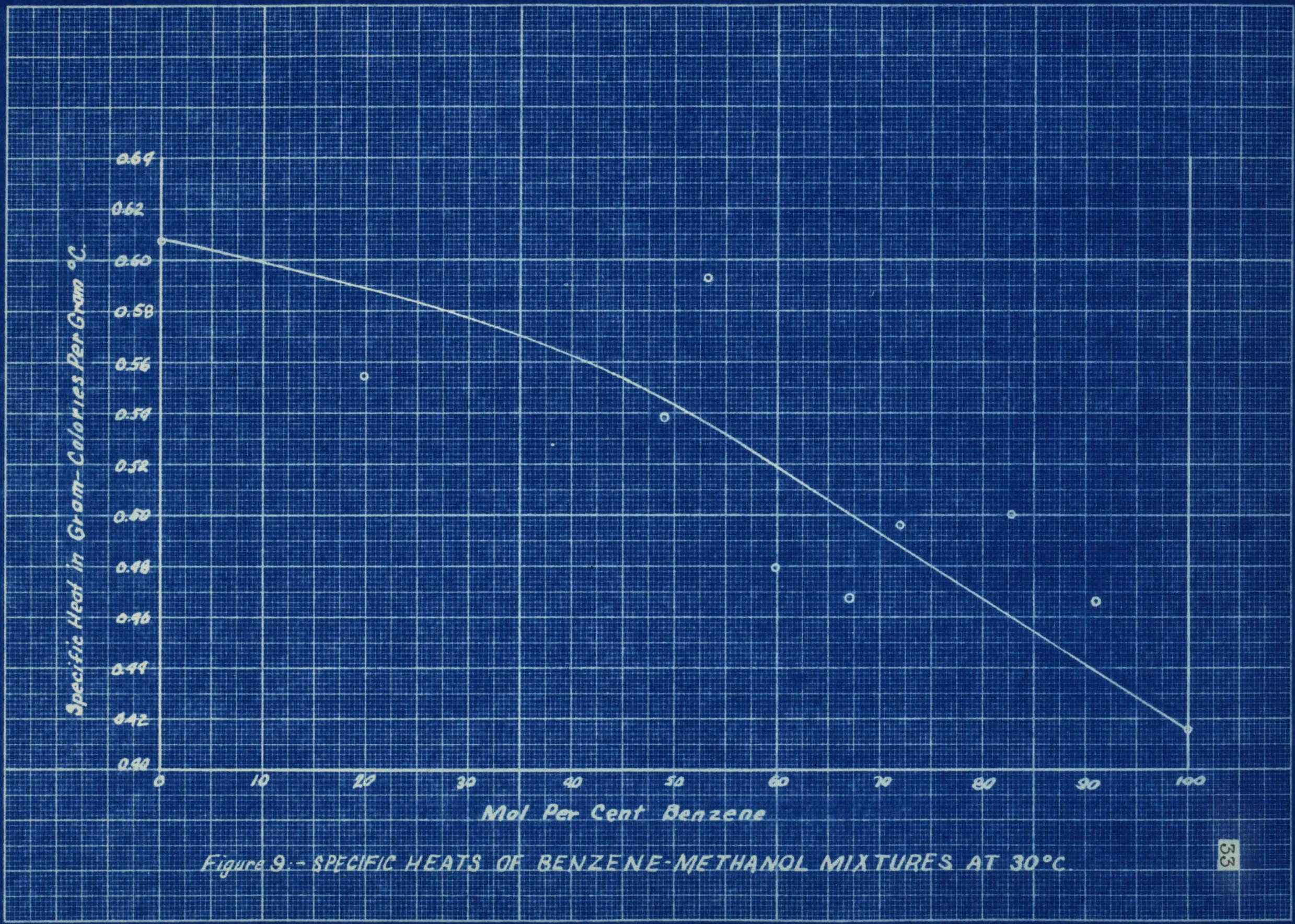




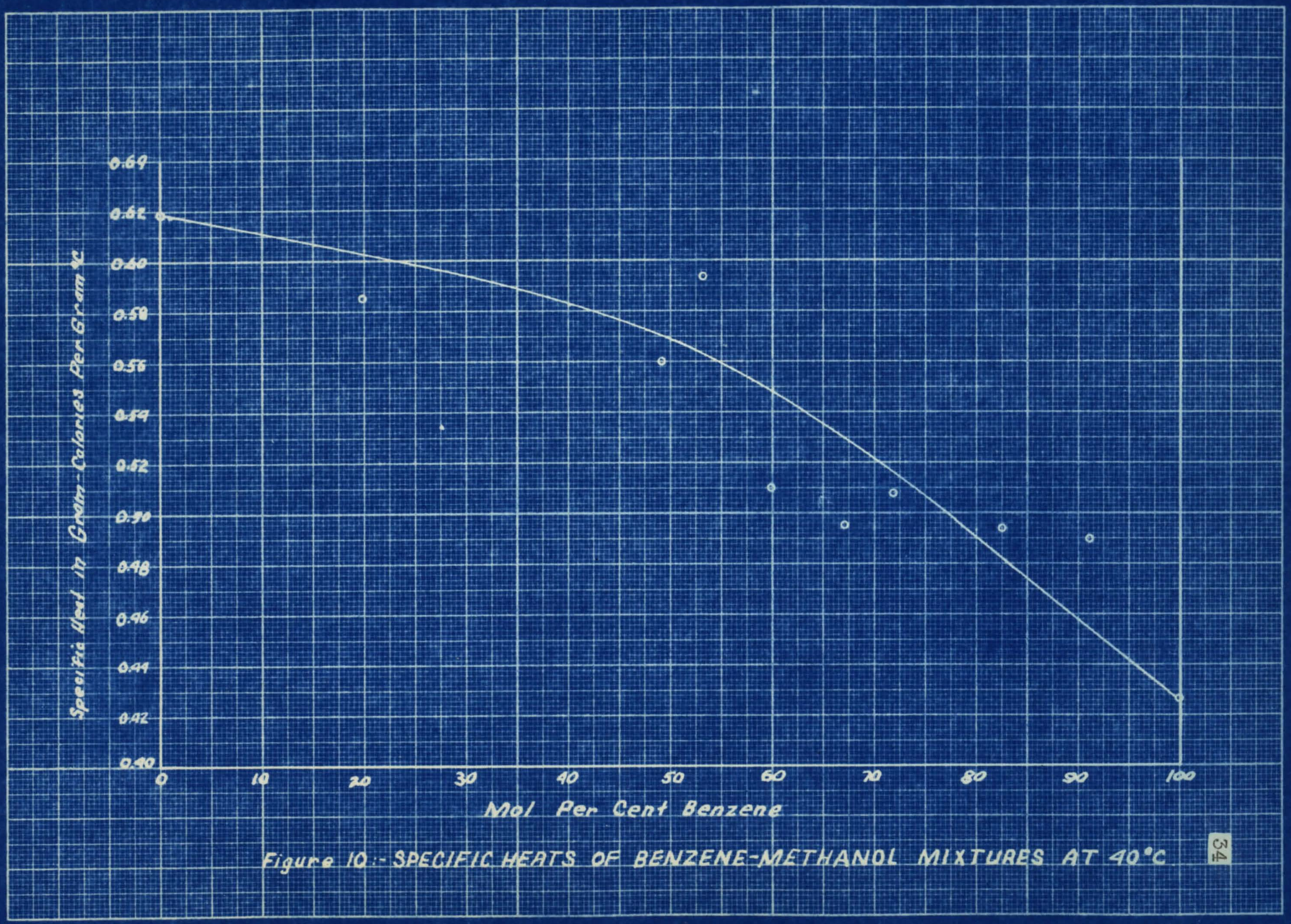




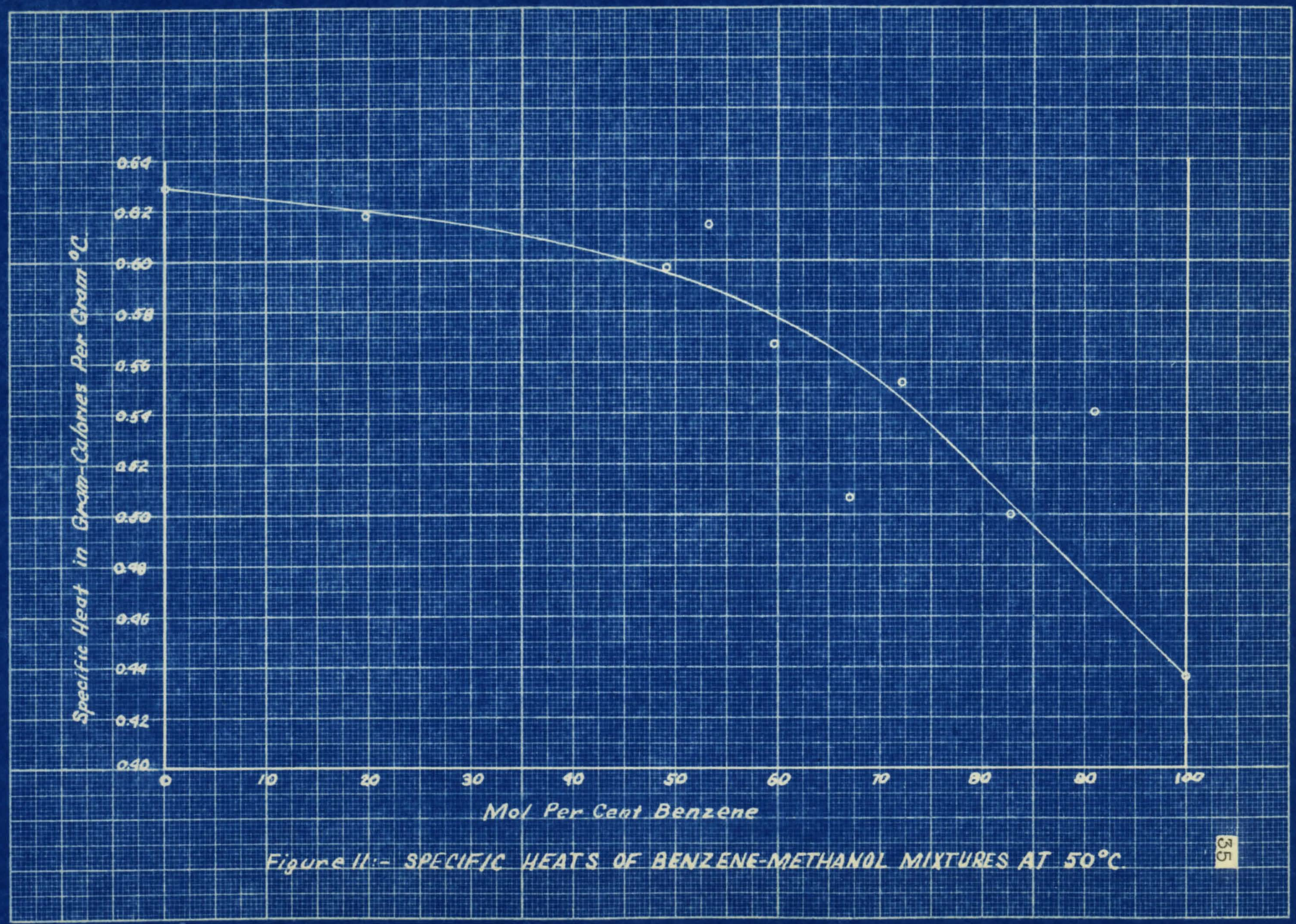




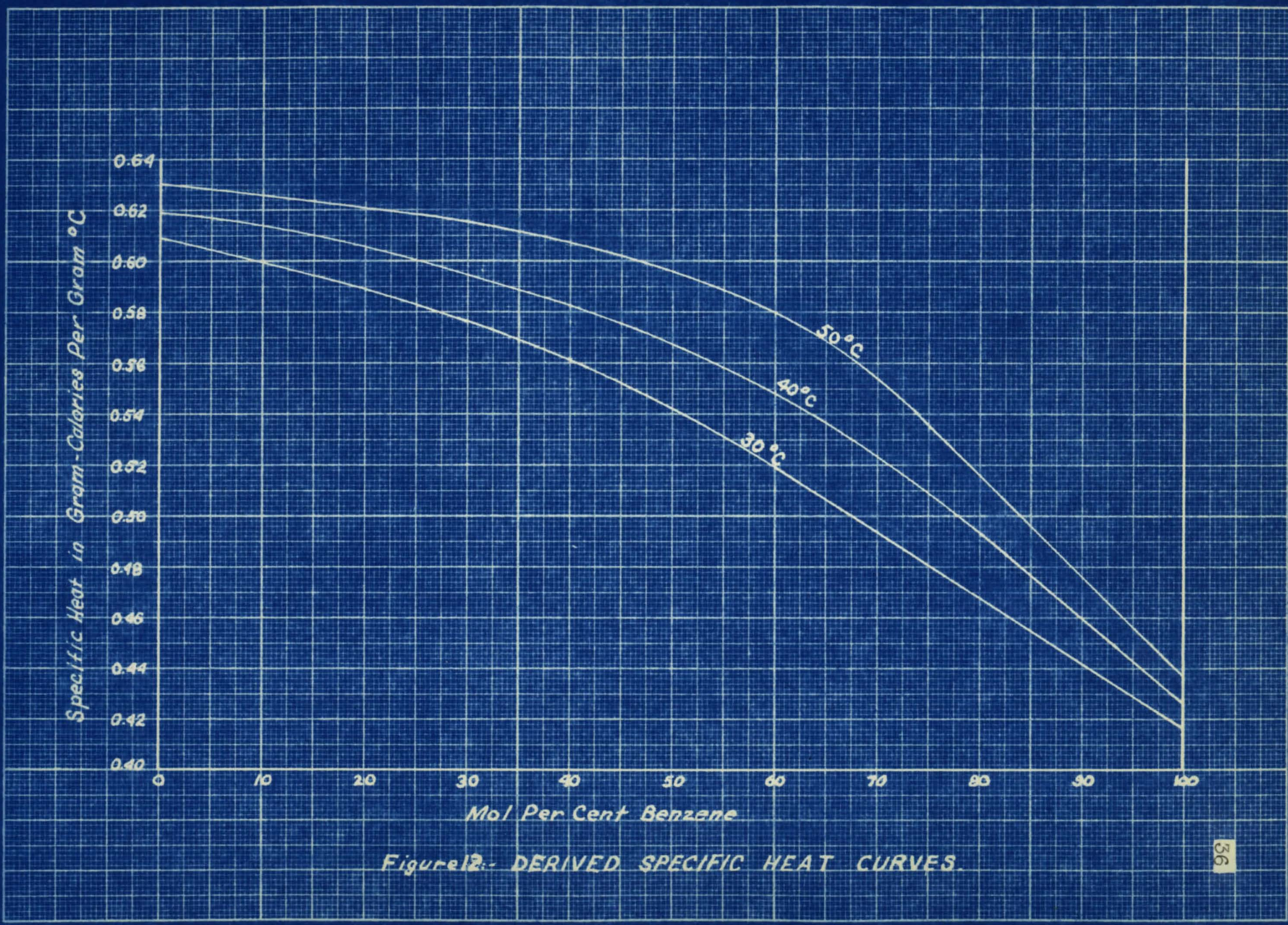


DISGUSSION OF RESULTS 
The density-composition curves follow normal expectations. The curve for volume per cent composition versus density is practically a straight line. This is as would be expected since the density is a physlcal property and since there is almost no reduction in volume upon the mixing of the two materials.

The curve for mol per cent composition versus density is therefore markedly different from the first due to the effect of different molecular weights and densities of the components.

In a like manner, the curves of composition versus refrective index Indicate a volume per cent composition versus refractive index as practically a straight line. The curve for mol per cent composition versus refractive Index deviates as in the previous property.

In the case of the bolling point diagram, it would be expected that the minimum boiling mixture would occur closer to one of the pure materials than the other. This is because of the different nature of the two materials. Benzene is definitely a non-polar compound while the methanol is a polar compound.

The equilibrium diagram follows the bolling point diagram in that the two sections of the curre are not balanced.

The erratic nature of the data in the specific heat muns is reflected in the curves of figure 8. It is obrious 
that many of these points are in error and the series of graphical averaging plots (figures 9, 10, and 11) were made in an attempt to show which values could be discarded. Specific heats of binary mixtures should be continuous functions both in respect to temperature and composition. This graphical procedure is allowable only under these conditions. The results as shown in figure 12 will necessitate confirmations before complete acceptance is obtalned. 
40

CONCLUSIONS AND RECOMMENDATIONS 
The plots obtained as a result of the experimental work of this thesis can be employed in the solution of distillation problems. With the addition of a plot of composition versus enthalpy, all the data are available for the solution of a distillation problem by the method of Ponchon and Savarit.

It is recommended that the data of specific heats be substantiated by more experimental work. Several changes are necessary in order to eliminate some of the inaccuracies of this phase of the work.

These changes should be designed to eliminate, as much as possible, the loss in material as vapor from the system. W1th the present apparatus, the material loss amounted to only about 0.1 grams in 190 grams of mixture. However, on a heat basis, this is a large quantity of loss since the heat of vaporization is very high compared to the specific heat of the solution. 
APPENDIX 


\section{ACKNOWLEDGMENT}

The author wishes to acknowledge the grant of money and the tuition by the University of Loulsvilie which made this research possible. 


\section{IITERATURE CITED}

(I) Badger, W. L., and McCabe, W.I., "Elements of Chemical Fngineering", McGraw-H1ll Publishing Company, New York, N. Y. p. 320 (193I)

(2) International Critical Tables, McGraw-Hill Publishing Company, Now York, N. Y. Vol. 1, p.80 (1933)

(3) Jasper, J. J., "Laboratory Methods of Physical Chemistry", Houghton Mifflin Company, Cambridge, Mas sachusetts p. 163 (1938)

(4) Othmer, D. F., Ind. Eng. Chem. Vol. 20, 743 (1928)

(5) Robinson, C. S., and Gillialnd, E. R., "Elements of Fractional Distillation", McGraw-Hill Publishing Company, New York, N. Y. p. II6 (1939)

(6) Ibid., p. 107

(7) 1bid., p. 114

(8) Vold, R. D., J. Am. Chem. Soc., Vol. 59, 1515-2I (1937) 
VITA

Samuel Rosenberg, son of Benjamin and Sadie Rosenberg, was borm at Trenton, New Jersey, on July 26, 1918.

He attended grade school at Trenton unt1l 1929, when his family moved to Louisville, Kentucky. Here he attended Louisville Male High School and graduated in June, 1936.

In September, 1936 he entered the speed Scientific School of the University of Loulsville where he was a member of Sigma Tau, national honorary engineering fraternity; Theta Chi Delta, national honorary chemistry fraternity; and the student branch of the A. I. Ch. E.

In $\operatorname{Jun} \theta, 1940$, he recelved the degree of Bachelor of Chemical Engineering, and was awarded a graduate assistantship in the Department of Chemical Englneering at the University of Ioufsville. In October, 1941, he recelved the degree of Master of Chemical Engineering from the University of Louisvilie. 